\title{
Potential impact of climate change on the New Zealand electricity market
}

\author{
Golbon Zakeri \\ Engineering Science \\ University of Auckland \\ g.zakeri@auckland.ac.nz
}

\author{
Geoff Pritchard \\ Statistics \\ Lucas Moniotte \\ Liam Shanker \\ Genie Energetique et Environnement Engineering Science \\ University of Auckland INSA Lyon University of Auckland \\ g.pritchard@auckland.ac.nz Lucas.Moniotte@insa-lyon.fr $\underline{\text { 1sha335@aucklanduni.ac.nz }}$
}

\begin{abstract}
The New Zealand electricity sector, dominated by hydroelectric generation, is arguably highly vulnerable to climate change. While the current generation resources seems adequate for maintaining security of supply, in the face of climate change, inflow patterns may change drastically and we need to reassess the adequacy of generation resources. We introduce a novel process for adjusting the historical inflow models to represent various climate scenarios. Our methodology is general and can be applied to any inflow data set coupled with potential climate scenarios, to produce post climate change inflow distributions. We will then use Dynamic Outer Approximation Sampling Algorithm (DOASA) [1] with a distribution of historical inflows, as well as post climate change inflows, to balance the hydro-thermal generation scheduling for New Zealand. This, in turn, provides some insight into the possible effects of climate change on the electricity generation profile of New Zealand. We find that by 2035, at a national scale, the average price and generation is unlikely to be much affected, but the seasonality within these parameters will likely change. Within this near future horizon, we report that a reduction in annual thermal generation may be offset by an average increase in hydroelectric generation along the Waikato river hydro scheme. However, by 2100, we anticipate a degree of stress in the market due to an expected decrease in water availability. In the worst case, we see that thermal generation will increase to ensure the security of supply, and higher prices may be observed.
\end{abstract}

\section{Introduction}

Climate change is likely to have an effect on inflow patterns in various countries and jurisdictions. Concurrently, many jurisdictions are transitioning to renewable forms of energy generation. New Zealand is a country that is striving to achieve significantly lower levels of $\mathrm{CO}_{2}$ and other green house gas emissions by 2050 and to this end is planning much heavier reliance on renewable sources of electricity generation. Currently, renewable sources of electricity contribute approximately $85 \%$ of supply to the New Zealand Electricity Market of which $60 \%$ is from hydro-generation [2]. New Zealand is strongly dependent on effectively managing the interplay between controllable storage of water for generation and thermal resources. Thermal fuels, such as natural gas and coal, provide security of supply in years where water is scarce. As such, the sectors vulnerability to climate change is of great interest to the electricity industry and New Zealand as a whole.

It is generally accepted that there will be changes in the climate attributable to increasing amounts of greenhouse gas emissions in the atmosphere. The impacts of these changes can include more frequent ex-tropical cyclones, extreme rainfall events, fires, higher storm surges and more days with extremely high temperatures (New Zealand Climate Change Centre, 2010). Consequently, the trends observed in historical meteorological data do not necessarily translate to what we can expect in the future. Water availability and hydropower generation is likely to be affected by climate change subsequently altering the seasonality of inflows into reservoirs. There is a large and longstanding body of literature on the topic of stream flows (see e.g. $[3,4,5])$. Much of the literature to date is concerned with the effects of climate change on water resources for drought risk characterization and water resource vulnerability (see e.g. $[6,7,8]$ ). As the main objective of our study is to gain some insight into the impact of climate change on the electric sector of a hydro-rich jurisdiction, we need inflow models that can be incorporated into hydro-electric reservoir planning via stochastic optimization. This places some very particular requirements on them. There should be an unforeseeable random innovation at every time step (so that the optimal strategy cannot be unrealistically clairvoyant), but the innovation should ideally take the form of finitely many possible scenarios 
(so that the optimal strategy is computable). It is also important that the auto-correlation structure of inflows is properly captured. In the past this has been done using auto-regressive lag-1 models (see e.g. [9]) or auto-regressive moving average models (see e.g. [10]), however their shortcomings, mainly the restrictive modelling assumptions, have been recognized (see [11]). Hydro-electric reservoir planning through this kind of stochastic optimization was first explored in [12].

This paper details the construction of a framework to model historical inflow trends through quantile regression models, which can simulate these trends in stochastically generated sequences. Quantile regressions is a versatile and relatively non-restrictive form of modelling inflows. We, then, develop a novel process for adjusting these models to describe the climate scenarios defined by the National Institute of Water and Atmospheric Research (NIWA). We use these adjusted models to study the hydrological and hydropower impact of these changes within the New Zealand Electricity Market (NZEM). In this study, we have left the demand, the configuration of the transmission grid and the rest of the electricity generation fleet as they are today (in 2019). Factors such as electricity demand may of course be changed to follow a distribution of its own following climate change, such as investigated in [13]. While we use New Zealand as our case study, our methods are general and may be applied anywhere. Utilizing New Zealand as a case study makes this a real world problem. All analysis in this paper, unless otherwise stated, was conducted using the statistical software R (R Core Team, 2016). All code and data is available from the authors upon request.

\section{Methods}

\subsection{Inflow models}

Our baseline hydro inflow model is similar to that of Pritchard [14]. Weekly inflows have a distribution modelled by a quantile regression ([15]) of the following form:

$$
F_{t}=q(t)+p(t) F_{t-1},
$$

where $F_{t}$ is the inflow at time $t$ and

$$
p(t)=\beta_{0}+\sum_{k=1}^{2}\left(\beta_{k}^{s} \sin (k \omega t)+\beta_{k}^{c} \cos (k \omega t)\right)
$$

(similarly $q(t)$ ) is a second-order trigonometric polynomial. Here $\omega=2 \pi$ per annum and $\beta_{0}, \beta_{k}^{s}$, and $\beta_{k}^{c}$ are fitted coefficients. The model resembles a lag-1 autoregressive process, except that the coefficients may slowly vary to reflect annual seasonal variation in the distribution and the autocorrelation structure of inflows. Figure 1 illustrates 11 fitted models of this kind, corresponding to the $1 \mathrm{st}, 2.5 \mathrm{th}, 5 \mathrm{th}, 10 \mathrm{th}, 30$ th, 40th, 50th, 70th, 85th, 95th, and 99th percentiles of the conditional distribution of inflows in the Manapouri catchment (see below). These were chosen to best represent the spread in the data. Higher resolution has been used at the extremes to better represent high and low inflow events.

\subsection{Synthetic inflow generation}

A set of quantile regressions such as those depicted in Figure 1 can be turned into a stochastic model for the inflows in a single catchment. At each time step $t$, one of the regressions is selected at random and used to predict the inflow $F_{t}$ via (1). Simulation of the resulting stochastic process provides a means of generating arbitrarily many synthetic inflow sequences. Note that although this process has a continuous state space, the random innovation at each step is discrete (with only finitely many possibilities).

The random choice among available regressions could be made in several ways; some possibilities are shown in Figure 2. However, the distribution of inflows will be best matched if the probability of a particular regression being selected reflects the percentile of the distribution for which the regression was fitted. This leads to the following scheme (denoted "Uniform Sampling" in Figure 2): if model $i$ is a quantile regression for the $p_{i}$ quantile $\left(0<p_{i}<1\right)$, then it should be chosen with probability $\mid\left\{p:\left|p-p_{i}\right|<\right.$ $\left.\left|p-p_{j}\right| \forall j \neq i\right\} \mid$. For example, if the regressions are for the $0.05,0.2,0.6$, and 0.9 quantiles, the corresponding probabilities are $0.125,0.275,0.35$, and 0.25 . This choice is made independently at different time steps.

To extend this technique to a multivariate process representing several catchments, we must consider spatial correlations between the catchments. A fairly simple way of handling this is possible if the catchments can be grouped into clusters, in such a way that the inflows have high spatial correlation within clusters and low correlation between clusters.

In the case of New Zealand, this can be achieved with two clusters: North Island and South Island. An alternative three-cluster solution, with somewhat greater modelling accuracy, splits the South Island into one cluster comprising the Waitaki system and another comprising the Clutha and Manapouri catchments.

Each catchment has its own set of regressions of the form (1); the quantiles $p_{i}$ have the same values 

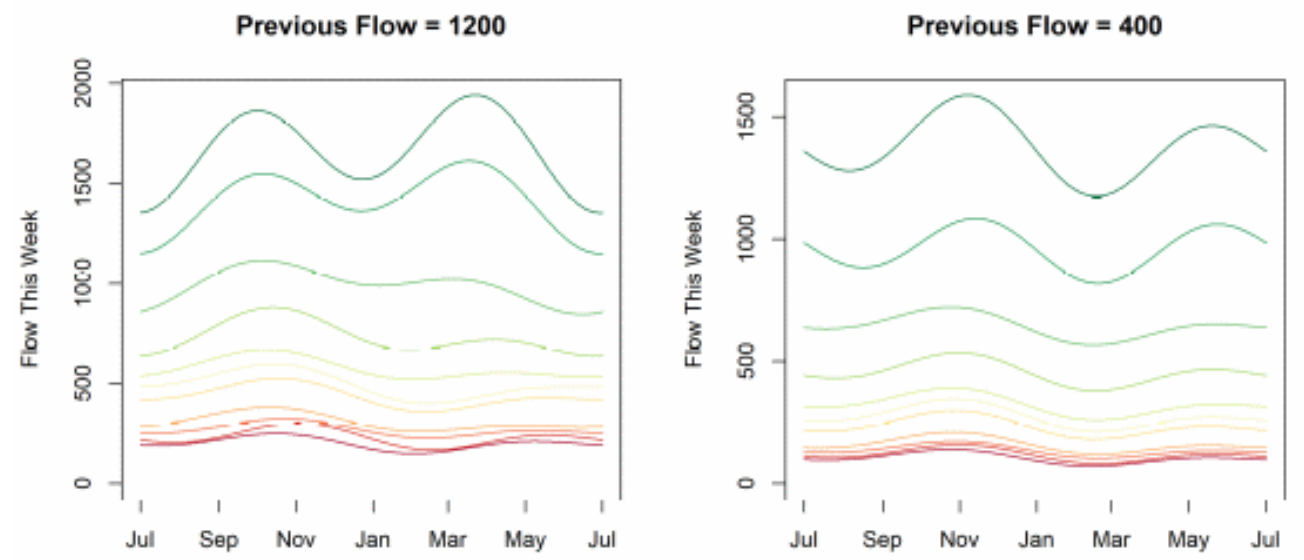

Figure 1. Quantile regression modelling demonstrating seasonal patterns.

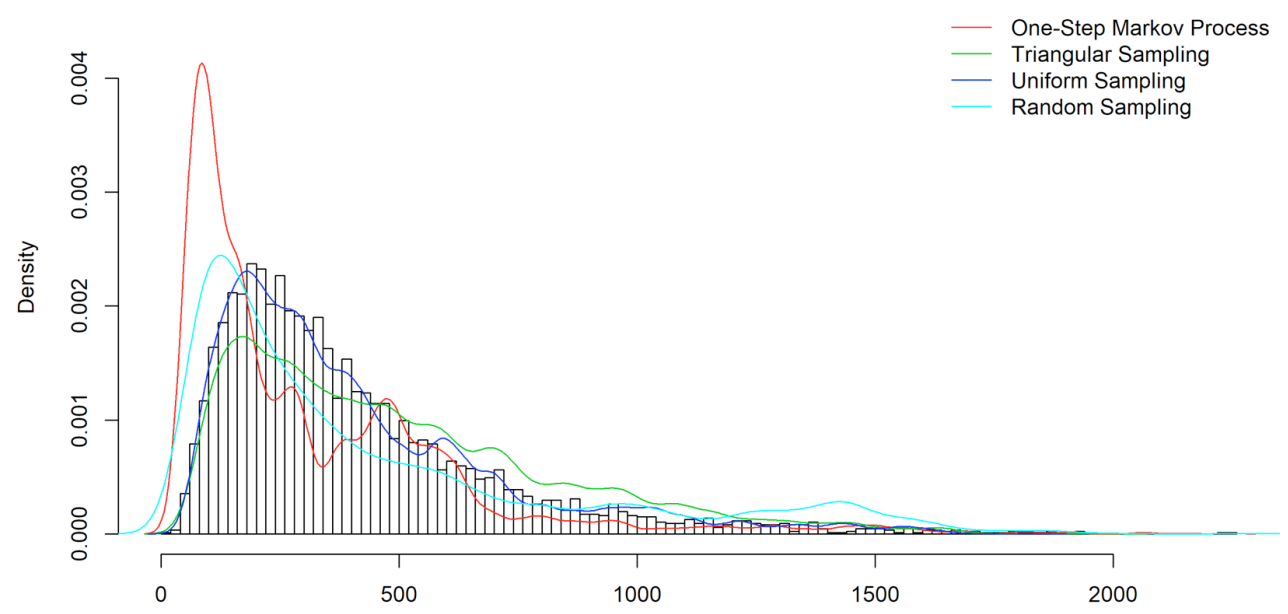

Figure 2. Comparison of various sampling techniques to the historical data for Manapouri inflows.

for all catchments in a cluster. The random choice of regression model at any time step $t$ is shared between all catchments in a cluster, but is independent between clusters.

\subsection{Adjusting models for climate change}

Having established a stochastic model of type (1) for inflows in the (assumed stationary) present-day climate, we now consider how to modify it to reflect inflows in other climates. Our starting point is the predicted changes in precipitation and snowpack given in [16] and [17] for the standard set of Representative Concentration Pathways established by the IPCC ([18]). For example, the RCP8.5 pathway for the near future (to the year 2035 ) is associated with the (relative) changes to inflows into the six major New Zealand catchments given in Table 1.
Table 1. Seasonal inflow adjustments under NF RCP8.5, for lakes Manapuri, Tekapo, Pukaki, Ohau, Hawea and Taupo.

\begin{tabular}{|c|cccc|}
\hline \hline Catchment & Summer & Fall & Winter & Spring \\
\hline MAN & -0.08 & 0.01 & 0.12 & -0.05 \\
TEK & -0.1625 & 0.0625 & 0.1875 & -0.0625 \\
PUK & -0.1625 & 0.0625 & 0.1875 & -0.0625 \\
OHA & -0.15 & 0.05 & 0.2 & -0.1 \\
HAW & -0.0875 & -0.05 & 0.1875 & -0.075 \\
TAU & 0.05 & -0.025 & 0.125 & -0.025 \\
\hline
\end{tabular}


In order to modify our stochastic inflow models in a way that reflects these changes to the marginal distributions of inflows, we developed the following process. First, the value of $F_{t}$ given by (1) is tabulated for all inputs $\left(t, F_{t-1}\right)$ in a discretized grid: 52 equally-spaced times of year $t$ and an equally-spaced sequence of prior-inflow values between zero and the maximum historically observed inflow for the catchment. For each entry in this table, the $F_{t-1}$ and $F_{t}$ values are adjusted by multiplication by the appropriate entry from Table 1 (or its counterparts for other concentration pathways). The quantile regression models are then re-fitted to this adjusted data.

Synthetic inflow sequences from the new models can then be checked to ensure that the required distributional changes have been effected, as illustrated in Figure 3.

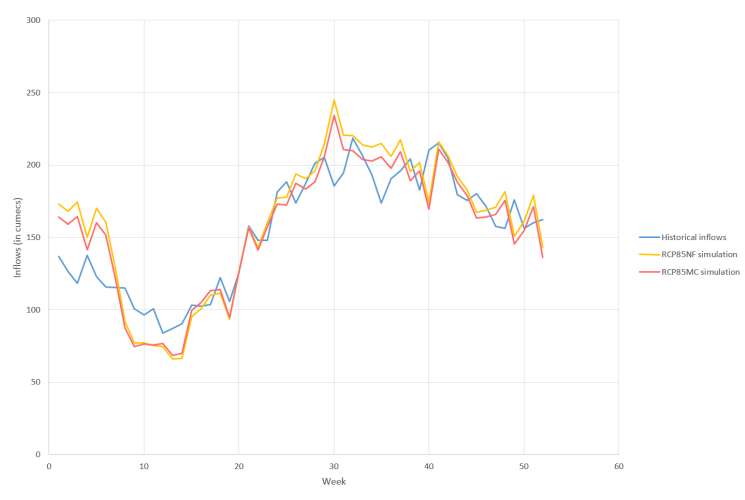

Figure 3. Average inflows for lake Taupo for historical, near future and mid-century post climate scenarios.

\section{Hydro-thermal scheduling for efficient electricity generation}

In any electricity market where a significant part of generation is from hydro resources, it is important to consider the distribution of inflows over a planning time horizon, in order to find the most efficient balance of hydro versus thermal resource usage over that time horizon. Such problems are often captured as stochastic programs where a reservoir's water level (or available capacity for generation) is carried from one time epoch to the next and a distribution of inflows captures the main uncertainty in the problem. Solution techniques for this type of problem date back to the seminal paper of Pereira and Pinto [12], although there have been continual algorithmic improvements for this type of problem (see e.g. [19]).

To obtain the optimal balance of hydro-thermal utilization in pre and post climate scenarios we used
Dynamic Outer Approximation Sampling Algorithm (DOASA), a software developed for this purpose and tailored to the study of New Zealand's electricity system provided by the New Zealand Electricity Authority (see [1]). The DOASA model uses weekly stages. A calendar year is divided into 52 weeks. A plan year is typically a year of 52 weeks with the starting week chosen to be a particular week in the plan year and a fixed number of weeks used. Inflows are sampled from a file that records weekly inflows. We are therefore able to provide sample paths of inflows for each catchment in DOASA using our methodology above for both historical and post climate distributions. The New Zealand system is represented in DOASA as depicted in Figure 4 below. In particular DOASA considers the main six hydro catchments of New Zealand and assumes a three node linear representation of the NZ transmission network. We note that DOASA treats inflows as stage-wise independent. Clearly this assumption is unrealistic, so to compensate DOASA uses an ad hoc dependent inflow adjustment. For specific assumptions on load blocks, value of lost load and other details of the model including the dependent inflow adjustment we refer the reader to the DOASA manual available from [1].

Once we apply DOASA to the sequences of inflows generated from the post climate change distributions we find that the resulting thermal costs increase in almost every week of the year. This demonstrates significant increase in the utilization of thermal resources particularly during the summer in the Southern hemisphere. Such results are note-worthy as they may have implications in terms of penetration of renewable resources of energy such as wind, which is intermittent and requires so called firming. It may be that with further penetration of wind, we may need even more thermal back up due to the changing inflow patterns. The thermal utilization results may also be of interest to find the best time of year for unit maintenance. This likely not to be the summer season post climate change.

It is also interesting to track the lake levels of a catchment throughout the year, when hydro-thermal scheduling is utilized. These so called spaghetti graphs are depicted in Figures 6, 7 and 8 for the historical, near future and mid-century projections of distributions of inflows into lake Taupo. We note that using post climate change inflow scenarios result is wider volatility in the lake levels and the levels approach their minimum possible allowed level more frequently. This means that there are plausibly greater risks of outages in the future. One use of synthetic inflow sequences, as generated by our method, is that it allows for study of rare events. For 


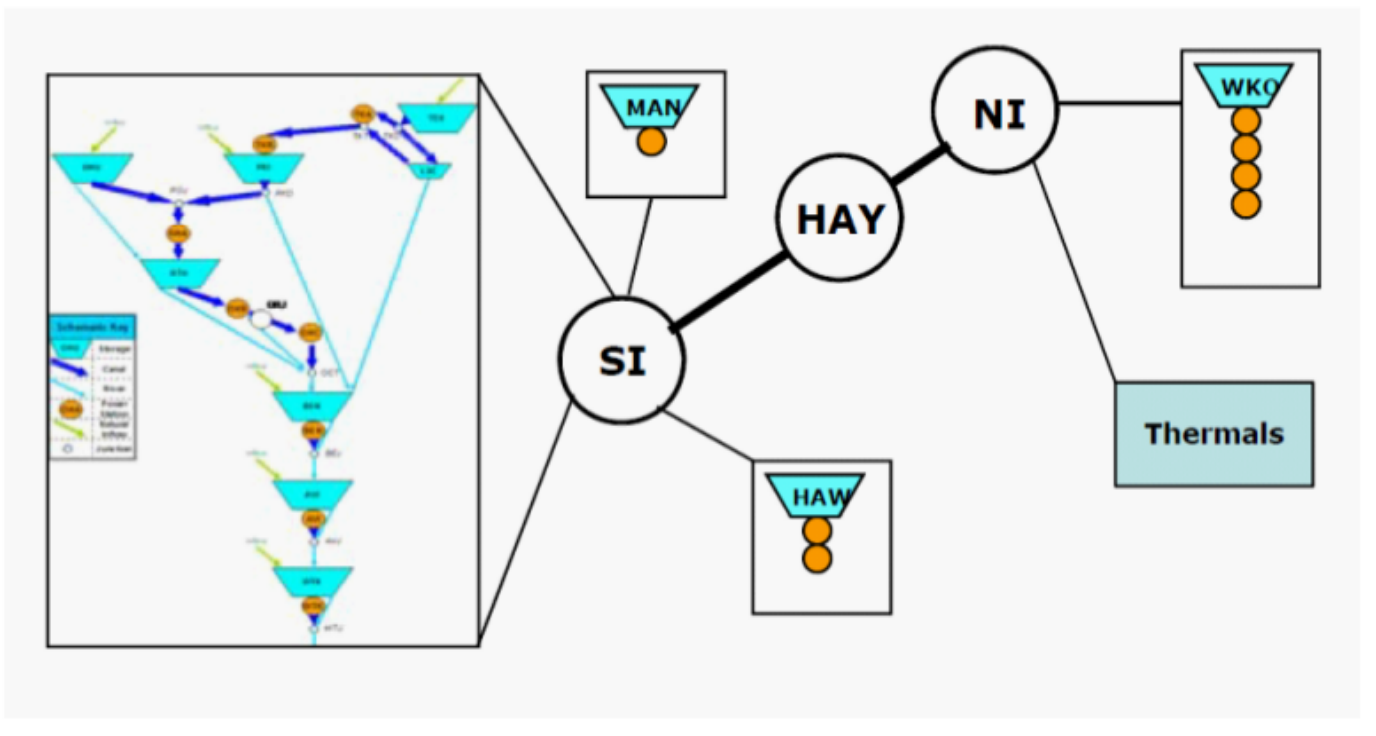

Figure 4. NZ electricity system as represented in DOASA.

example we would be in a position to study what a one in one hundred year flood may be like.

\section{Conclusions}

We have established a frame work for producing synthetic sequences of inflows into hydro lakes. This methodology is interesting and useful as post climate change many countries and jurisdictions will experience different patterns of inflows into their hydro catchments. Of particular interest, is the impact of this varried distribution on the optimal operation of an electricity market. We have presented a case study for the New Zealand electricity market and what may be note worthy in post climate inflow scenarios. Our methodology is general and can be used in any setting.

\section{References}

[1] "Doasa tool," Available from https://www.emi.ea.govt.nz/Wholesale/Tools/Doasa, 2017.

[2] "Renewable statistics," Available from www.mbie.govt.na, 2017.

[3] N. C. Matalas, "Mathematical assessment of synthetic hydrology," Water Resources Research, vol. 3, pp. 937-945, 1967.

[4] M. B. Fiering and B. B. Jackson, "Synthetic streamflows," Water Resources Monograph, vol. 1, 1971.

[5] R. M. Hirsch, "Synthetic hydrology and water supply reliability," Water Resources Research, vol. 15, pp. 1603-1615, 1979.
[6] J. D. Salas, C. Fu., A. Cancelliere, D. Dustin, D. Bode, A. Pineda, and E. Vincent, "Characterizing the severity and risk of drought in the poudre river, colorado,", Journal of Water Resource Planning Management, vol. 131, pp. 383-393, 2005.

[7] N. Wanders and H. A. J. Van Lanen, "Future discharge drought across climate regions around the world modelled with a synthetic hydrological modelling approach forced by three general circulation models," Natural Hazards and Earth System Sciences, vol. 15, pp. 487-504, 2015.

[8] A. Nazemi, S. Wheater, H., K. P. Chun, and A. Elshorbagy, "A stochastic reconstruction framework for analysis of water resource system vulnerability to climate-induced changes in river flow regime," Water Resources Research, vol. 49, pp. 291-305, 2013.

[9] H. A. Thomas and M. B. Fiering, "Mathematical synthesis of stream flow sequences for the analysis of river basin simulation," Design of Water Resources Systems, vol. Edt. Maas et al., 1962.

[10] J. D. Salas, C. Fu., and J. T. B. Obeysekera, "Arma model identification of hydrologic time series,", Water Resources Research, vol. 18, pp. 1011-1021, 1982.

[11] A. Sharma, D. G. Tarboton, and U. Lall, "Streamflow simulation: A nonparametric approach," Water Resources Research, vol. 33, pp. 291-308, 1997.

[12] M. Pereira and L. Pinto, "Multi-stage stochastic optimization applied to energy planning," Mathematical Programming, vol. 52, pp. 359-375, 1991.

[13] Y. Chen, B. F. Hobbs, H. Ellis, C. Crowley, and F. Jutz, "Impacts of climate change on power sector nox emissions: A long-run analysis of the us mid-atlantic region,", Energy Policy, vol. 84, pp. 11-21, 2015.

[14] G. Pritchard, "Stochastic inflow modelling for hydropower scheduling problems," European Journal of Operations Research, vol. 246, pp. 496-504, 2015.

[15] R. Koenker, "Quantile regression,” 2005. 


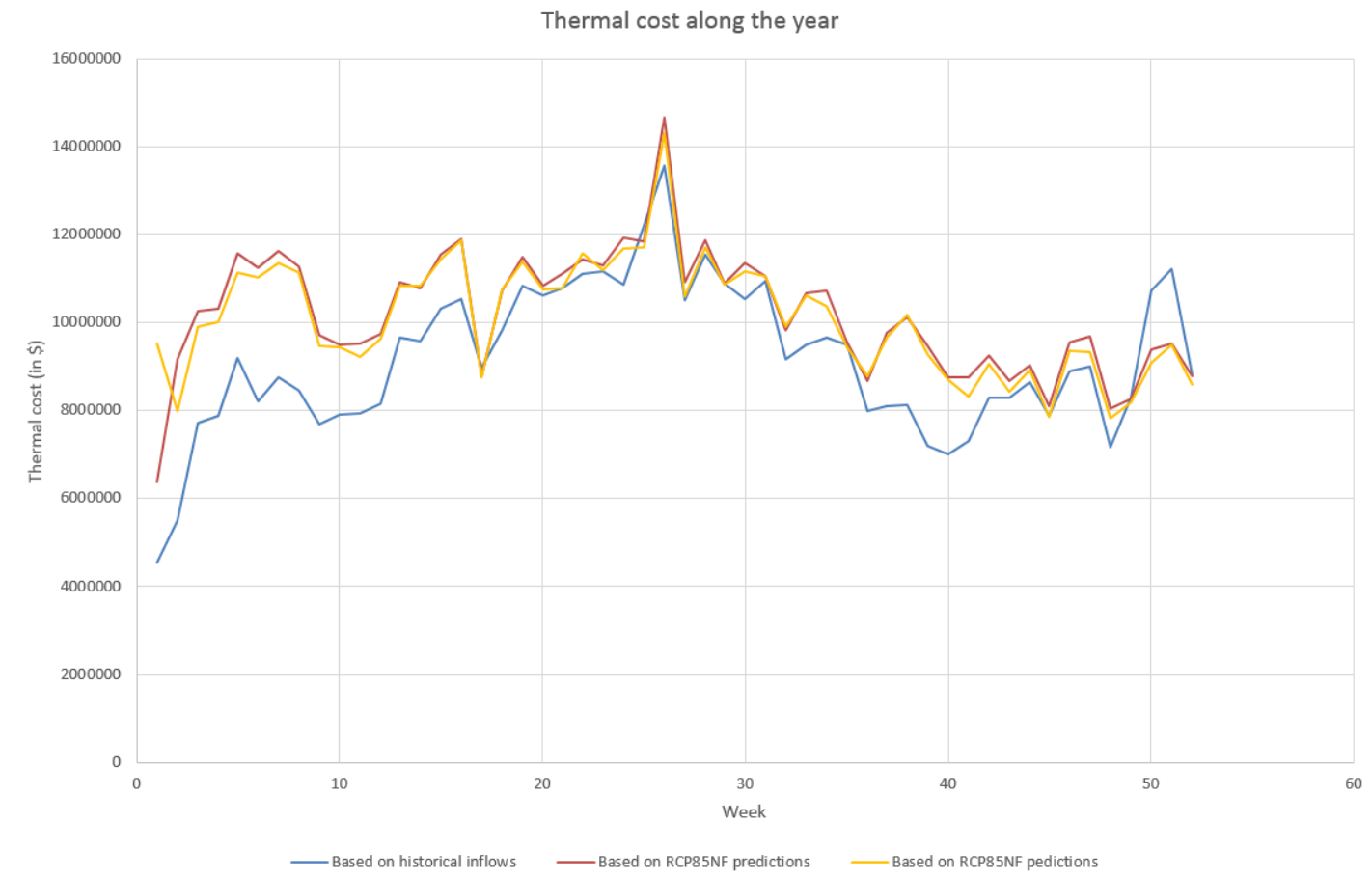

Figure 5. Average annual thermal costs for historical and post climate change electricity generation planned using DOASA for hydro-thermal scheduling.

[16] "Our future climate new zealand," Available from https://ofcnz.niwa.co.nz/, 2016

[17] J. Hendrikx and E. Hreinsson, "The potential impact of climate change on seasonal snow in new zealand," Theoretical and Applied Climatology, vol. 110, pp. 619-630, 2012.

[18] IPCC, "Climate change 2014: Synthesis report. contribution of working groups $\mathrm{i}$, ii and iii to the fifth assessment report of the intergovernmental panel on climate change," 2014.

[19] P. Girardeau, V. Leclere, and A. Philpott, "On the convergence of decomposition methods for multi-stage stochastic convex programs," Mathematics of Operations Research, vol. 40, pp. 130-145, 2014. 


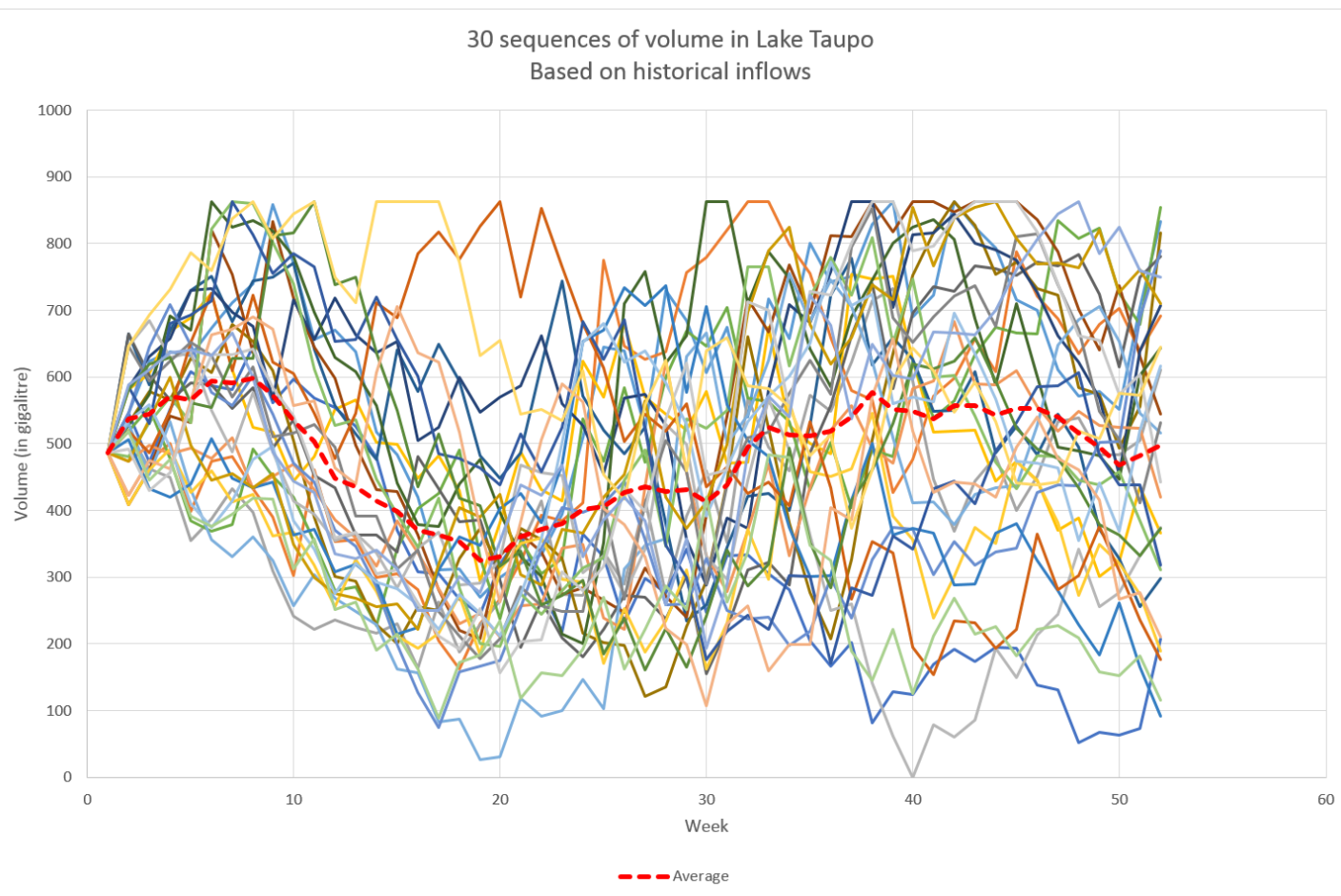

Figure 6. Optimal operational lake levels as output from DOASA for 30 samples of historical inflows for lake Taupo.

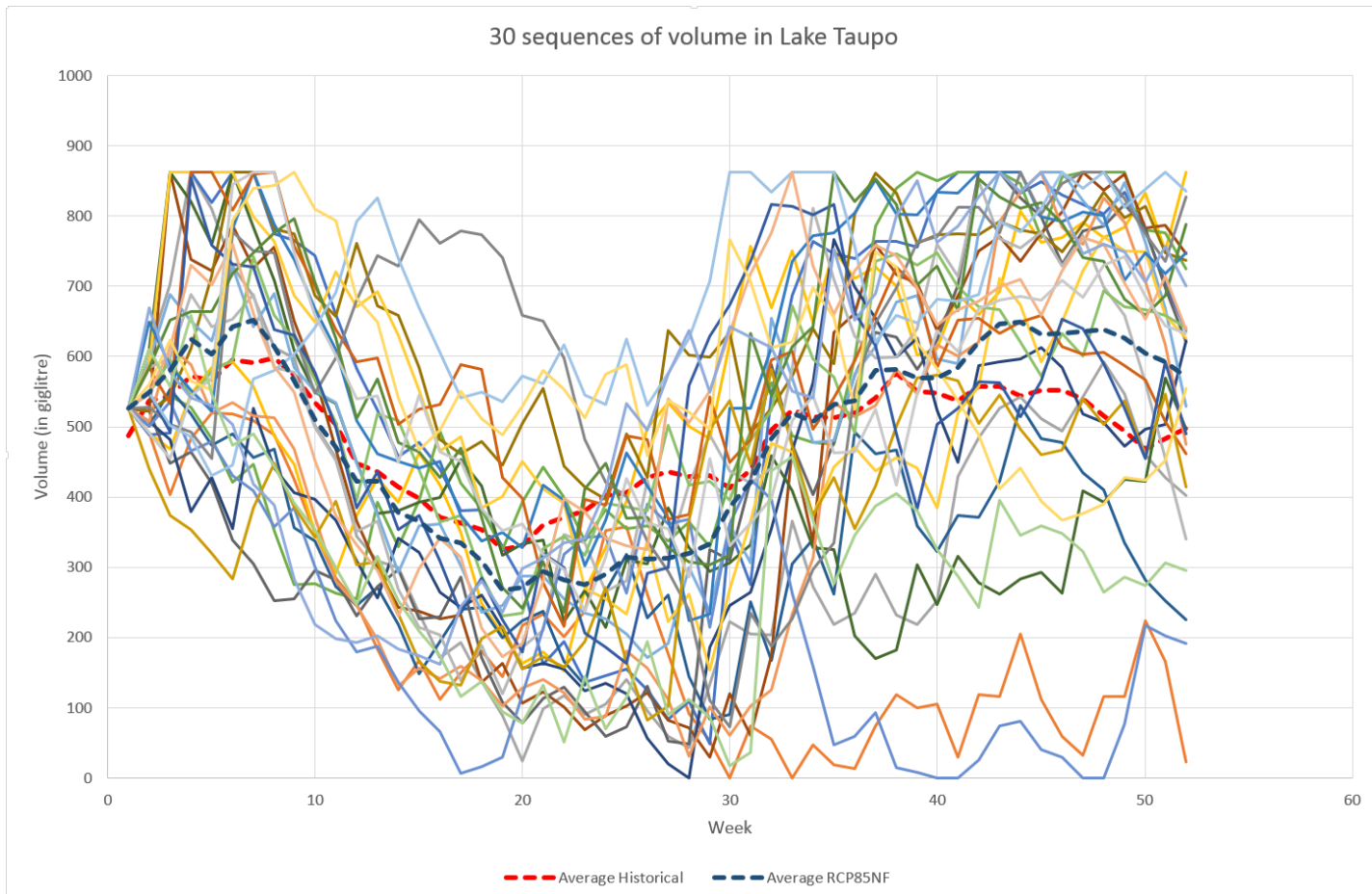

Figure 7. Optimal operational lake levels as output from DOASA for 30 samples of near future projected inflows under scenario RCP 8.5 for lake Taupo. 


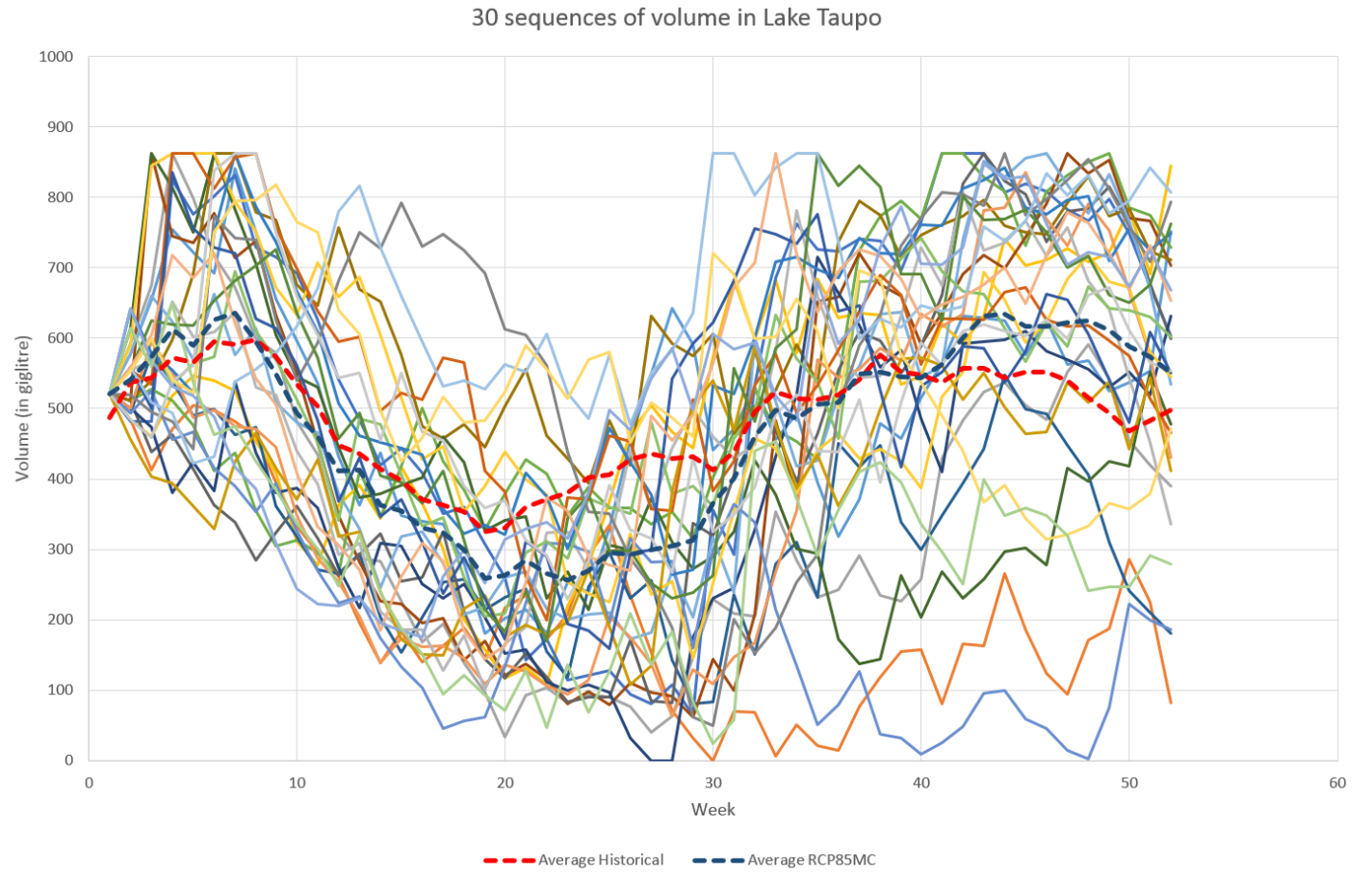

Figure 8. Optimal operational lake levels as output from DOASA for 30 samples of mid-century projected inflows under scenario RCP 8.5 for lake Taupo. 